\title{
Antifungal and anti-biofilm effects of shallot (Allium ascalonicum) aqueous extract on Candida albicans
}

\author{
Tzu Shan $\mathrm{Ng}^{1,2^{*}} \stackrel{\mathbb{Q}}{ }$, Ley Juen Looi ${ }^{3}$, Ban Shui Ong ${ }^{1}$, Pei Pei Chong ${ }^{1}$ \\ ${ }^{1}$ Department of Biomedical Sciences, Faculty of Medicine and Health Sciences, Universiti Putra Malaysia \\ ${ }^{2}$ Department of Molecular Medicine, Faculty of Medicine, University of Malaya \\ ${ }^{3}$ Department of Environmental Science, Faculty of Environmental Studies, Universiti Putra Malaysia
}

\section{ART I CLE IN F O}

Article Type:

Original Article

\section{Article History:}

Received: 7 April 2018

Accepted: 10 September 2018

\section{Keywords:}

Allium ascalonicum

Shallot

Candida albicans

Antifungal activity

\begin{abstract}
A B S T R A C T
Introduction: The limited option to combat fungal threat has raised the interest in seeking alternative anti-fungal compounds. This study aimed to determine the antifungal property of aqueous-extracted shallot (Allium ascalonicum) against Candida albicans, a medically important yeast pathogen. The anti-biofilm property of $A$. ascalonicum aqueous extract was also investigated.

Methods: The antifungal effect of A. ascalonicum aqueous extract on C. albicans was screened using disc diffusion assay and the minimum inhibitory concentration (MIC) was determined using broth macrodilution. Subsequently, the anti-biofilm property of $A$. ascalonicum aqueous extract was investigated using 2,3-bis(2-methoxy-4-nitro-5-sulfophenyl)-5-[(phenylamino) carbonyl]-2 H-tetrazolium hydroxide (XTT) reduction assay, crystal violet (CV) assay, and microscopic examination.

Results: A zone of C. albicans growth inhibition was observed at 10 and $20 \mathrm{~g} / \mathrm{mL}$ of $A$. ascalonicum aqueous extract. The MIC of $A$. ascalonicum aqueous extract was found at $10 \mathrm{~g} /$ $\mathrm{mL}$. Significant differences were found between $A$. ascalonicum aqueous extract -treated and non-treated C. albicans in term of biofilm formation activity (XTT assay) and the quantity of biofilm formed (CV assay).

Conclusion: Using a simple and inexpensive extraction procedure, this study revealed the antifungal property of $A$. ascalonicum aqueous extract, which could be useful in exploring novel antifungal compound.
\end{abstract}

Implication for health policy/practice/research/medical education:

Candidiasis remains as one of the prominent nosocomial infection disease and Candida biofilm is one of the main culprits associated with this deadly disease. The result showed the application of Allium ascalonicum aqueous extract in anti-Candida albicans growth and its biofilm activity. This simple and inexpensive method could be useful for the development of surface disinfectant in tackling the C. albicans biofilm issue in the clinical setting.

Please cite this paper as: Ng TS, Looi LJ, Ong BS, Chong PP. Antifungal and anti-biofilm effects of shallot (Allium ascalonocum) aqueous extract on Candida albicans. J Herbmed Pharmacol. 2018;7(4):236-242. doi: 10.15171/jhp.2018.36.

\section{Introduction}

There are about 1.5 million fungal species, where Candida is among the 300 pathogenic fungal species that causes $\sim 700000$ cases of infection, annually (1-3). Candida can be found as a commensal organism in healthy individuals (4). However, it may exploit the weakness of human defence mechanisms and develop candidiasis in the immunocompromised individual (5). Candidiasis may either be superficial, which involves the skin, hair, nails, oral and vaginal regions, or systemic, which affects the major body organs such as acute disseminated Candida septicemia infection (6-8). Among the pathogenic species of Candida, Candida albicans appears to be the leading causative agent of candidiasis $(>50 \%)$ and possesses high mortality rate $(9,10)$. This deadly systemic invasive candidiasis is suggested to be highly correlated with the wide-usage of the medical instruments such as catheter contaminated with Candida biofilm $(11,12)$. Statistically, fungus (particularly C. albicans) is the third leading cause of catheter-related infections as well as second highest colonization-to-infection with the highest crude mortality $(13,14)$. 
Biofilm is defined as the structural microbial communities that are attached to a surface and encased in a matrix of exopolymeric material (13) and often associated with the pathogenicity of Candida $(12,15)$. Known to be the virulent factor of Candida species, biofilm serves as the protective barrier for Candida species and contributes to boost the antifungal drug resistance. Additionally, biofilm also grants Candida species the ability to withstand the attack from host immune system and serves as reservoir site for re-infection $(5,13,16)$. Interestingly, the greater ability of C. albicans to form biofilm is linked with its dominance as the leading cause of candidiasis, in comparison to $C$. glabrata and C. tropicalis (17).

Despite the severity of candidiasis and fungal infections, fungi are often neglected by the public and funding bodies. In comparison to antibacterial remedies, there are only limited classes of antifungal agents available for physicians to combat Candida infections, namely polyenes, azoles, and echinocandins (18) which in turn may complicate the management of patients. In addition, the raising antifungal resistance reported worldwide has worsened the treatment outcomes (10). Therefore, several efforts, such as therapy through research and development of natural products, have been initiated to combat the threat posed by Candida species. The use of Allium ascalonicum (shallot) in food flavoring is known worldwide. Besides, shallot is also being employed in folk medicine since ancient time where shallot is described as "delicious food that stimulates the appetite during hot weather" (19). Shallot also possesses important medicinal value such as anti-oxidant (19) and anti-microbial property against Mycobacterium tuberculosis (21). Extensive efforts such as complex phytochemical analysis have been carried out to identify the potential active compounds, for example ascalin, and ascalonicoside A1/A2/B which may serve as the active antifungal compounds in A. ascalonicum $(19,22)$. These studies have highlighted the potential active antifungal compounds found in shallot bulb, however tedious efforts and resources are required for the purification and retrieval of these compounds. Thus, this study aims to use a direct and cost-effective aqueous extraction method to retrieve crude $A$. ascalonicum aqueous extracts and test the antifungal and anti-biofilm properties of the retrieved compounds. The results from this study would be useful for the development of inexpensive and economically sound surface disinfectant, particularly in tackling and managing the biofilms of $C$. albicans, which persists in the clinical settings (13).

\section{Materials and Methods}

Preparations of Allium ascalonicum aqueous extract Allium ascalonicum aqueous extract was prepared freshly each time before use. A stock solution of $20 \mathrm{~g} / \mathrm{mL}$ [weight/ volume (w/v)] of A. ascalonicum was prepared by grinding $20 \mathrm{~g}$ fresh clean shallot and ground in $1 \mathrm{~mL}$ of Phosphate
Buffer Saline (PBS). The extract was allowed to stand for 30 minutes at room temperature and centrifuged at 5000 rpm for 10 minutes. Then, the supernatant fluid was filtered through a sterile $0.22 \mu \mathrm{m}$ membrane filter (Merck Milipore, US). The required concentrations (w/v) were prepared by serial dilution from the stock solutions.

Disc diffusion assay

Preparations of paper disc impregnated with Allium ascalonicum extract

The fresh stock solution of $20 \mathrm{~g} / \mathrm{mL}(\mathrm{w} / \mathrm{v})$ of $A$. ascalonicum extract was serial diluted to prepare the serial concentrations of the extract $(2.5 \mathrm{~g} / \mathrm{mL}, 5.0 \mathrm{~g} / \mathrm{mL}, 10.0$ $\mathrm{g} / \mathrm{mL}$ and $20.0 \mathrm{~g} / \mathrm{mL}$ ) by using two-fold serial dilution with PBS which served as diluent. Paper discs with 6 $\mathrm{mm}$ diameter in size were prepared from ALBET $^{\circledR}$ filter paper (Hahnemühle, Germany) by using the sterile hole puncher. The paper discs were autoclaved at $121^{\circ} \mathrm{C}$ for 20 minutes for sterilization purpose before used. Then, the prepared paper discs were immersed in respective concentration solution for 10 minutes. Negative control disc was prepared by impregnating the paper disc with 20 $\mu \mathrm{L}$ PBS solution while Clotrimazole $(1.6 \mathrm{mg} / \mathrm{mL}$ ) (Sigma Aldrich) served as positive control. The discs were lifted and left covered at room temperature for 20 minutes before used.

\section{Preparation of Candida albicans strains}

Candida albicans ATCC 14053 was cultured on Sabouraud Dextrose Agar (SDA) (Becton \& Dickinson, USA) and was passaged twice from a single colony to ensure the purity. The identity of $C$. albicans was screened through CHROMagar $^{\mathrm{TM}}$ Candida (CHROMagar, French), which appeared as green colony. Further test on C. albicans colony was performed by amplifying its ITS 1-4 (Internal Transcribed Spacer Regions) through polymerase chain reaction (PCR), which yielded a 530 bp amplicon (23). The $C$. albicans culture with correct identity was then incubated overnight on SDA at $37^{\circ} \mathrm{C}$. Five colonies with the diameter larger than $1 \mathrm{~mm}$ were picked and suspended in $5 \mathrm{~mL}$ of PBS buffer. The yielded suspension was vortexed and cell density was adjusted by adding sufficient PBS buffer to achieve 0.5 McFarland Unit at 600 $\mathrm{nm}$ wavelength through microplate reader (BioTek, USA) in order to standardize the cell suspension with $1 \times 10^{6}$ to $5 \times 10^{6}$ cells per $\mathrm{mL}$. The inoculums were spread carefully onto SDA by using sterile glass hockey stick.

\section{Disc diffusion assay}

The plant extract disc was applied on the agar and allowed to stand at room temperature for 15 minutes to allow diffusion. Then, the agar plate was incubated at $37^{\circ} \mathrm{C}$ for 24 hours and the diameter of zone of inhibition was measured. 
Broth macrodilution

The broth microdilution method was performed as described previously with minor modification (24). A 0.5 McFarland Unit C. albicans cell suspension ( $1 \mathrm{x} 10^{6}$ to $5 \mathrm{x}$ $10^{6}$ cells per $\mathrm{mL}$ ) was prepared as described above. Then, $0.1 \mathrm{~mL}$ of the prepared cell suspension was mixed with $0.9 \mathrm{ml}$ of Sabouraud Dextrose Broth (SDB) (Becton \& Dickinson, USA) for further dilution of cells to $1 \mathrm{x} 10^{5}$ to 5 $\mathrm{x} 10^{5}$ cells per $\mathrm{mL}$.

Preparation of diluted Allium ascalonicum aqueous extract A total weight of $40 \mathrm{~g}$ fresh $A$. ascalonicum was ground in $1 \mathrm{~mL}$ of PBS to prepare a stock solution of $40 \mathrm{~g} / \mathrm{ml}(\mathrm{w} / \mathrm{v})$. The extract was allowed to stand for 30 minutes at room temperature then followed by centrifugation at $5000 \mathrm{rpm}$ for 10 minutes. The supernatant fluid was filtered through a sterile $0.22 \mu \mathrm{m}$ membrane filter (Merck Milipore, US). The required concentration, weight/volume (w/v) was prepared by serial dilution from the stock solutions as shown in Table 1.

\section{Broth inoculating}

A volume of $1 \mathrm{~mL}$ of each extract was pipetted into a $15 \mathrm{~mL}$ centrifuge tube, followed by $1 \mathrm{~mL}$ of C. albicans cell suspension and mixed well. The mixture tube was capped and left at room temperature for 15 minutes, then incubated at $37^{\circ} \mathrm{C} / 180 \mathrm{rpm}$ in a shaker incubator (Labnet, USA) for 24 hours. The cell growth activity was observed.

\section{Biofilm formation in 96-well microtitre plate}

The biofilm formation of $C$. albicans was performed as described by Pierce et al (25). A loopful of C. albicans cells was taken from culture stock of $C$. albicans in SDA and inoculated into $20 \mathrm{~mL}$ of SDB media. The culture was then incubated at $37^{\circ} \mathrm{C} / 180 \mathrm{rpm}$ for 16 hours in shaking incubator. After that, the cells were centrifuged at 3000 rpm for 5 minutes and the supernatant was removed. The sediment cells were resuspended in $2 \mathrm{~mL}$ of PBS for the cell washing purpose. The cells were centrifuged at 3000 rpm for 5 minutes again and the cell washing process was repeated twice. The cells were resuspended and adjusted to $0.5 \mathrm{McF}$ arland unit with $37^{\circ} \mathrm{C}$ pre-warmed RPMI 1640 media. Then, $100 \mu \mathrm{L}$ of cell suspension was loaded onto the 96-well microtitre plate. Next, $100 \mu \mathrm{L}$ of final concentration of plant extract varies from 0 MIC, 0.25 MIC, 0.5 MIC and 1 MIC were pipetted and mixed with cell suspension in respective wells. The 96well microtitre plate was covered with the lid and sealed with parafilm, followed by incubation for 24 hours at $35^{\circ} \mathrm{C}$. After incubation, the media from wells of 96-well microtitre plate was aspirated out carefully in order to prevent disruption of the biofilm formed at the bottom of well. The biofilm of each well was washed by adding 200 $\mu \mathrm{L}$ of PBS and the washing process was repeated for three times. Then, the plate was placed in invert position with a blotting paper to remove the residual of PBS.

Measurement of Biofilm Activity by using XTT \{2,3-bis (2-methoxy-4-nitro-5-sulfophenyl)-5-[(phenylamino) carbonyl]-2H-tetrazolium hydroxide\} reduction assay The measurement of biofilm activity through XTT assay was performed as described previously (25). Briefly, 4.95 $\mathrm{mL}$ of pre-made XTT $(0.5 \mathrm{~g} / \mathrm{L})$ was thawed and $50 \mu \mathrm{l}$ of menadione was added to thawed XTT. $100 \mu \mathrm{L}$ of XTT/ menadione was added to washed-biofilm in the wells of 96-well microtitre plate. Then, the plate was wrapped with aluminium foil and incubated in dark at $37^{\circ} \mathrm{C}$ for 3 hours. After that, $80 \mu \mathrm{L}$ of supernatant was transferred to a new 96-well microtitre plate and the plate was read by using microtitre reader (BioTek, USA) at the wavelength of 490 $\mathrm{nm}$.

Quantification of bioflim by using crystal violet assay The biofilm formed was quantified as described previously (26). Generally, the washed-biofilm was fixed by adding $100 \mu \mathrm{L}$ of methanol to each well for 15 minutes. Then, the supernatant was removed and the plate was left for air-dried. Subsequently, crystal violet (CV) solution was prepared by adding $1 \mathrm{~mL}$ of $90 \% \mathrm{CV}$ in $50 \mathrm{~mL}$ distilled water and $100 \mu \mathrm{L}$ of it was added to each well and left for 20 minutes. The excess $\mathrm{CV}$ was washed away under running tap water. A total of $150 \mu \mathrm{L}$ of $33 \%$ acetic acid was

Table 1. Preparation of serial concentrations of Allium ascalonicum extract

\begin{tabular}{|c|c|c|c|c|}
\hline Concentration $(\mathrm{g} / \mathrm{mL})$ & Stock solution at $40 \mathrm{~g} / \mathrm{mL}(\mathrm{mL})$ & PBS (mL) & Mixed with SDB & Final concentration yielded $(\mathrm{g} / \mathrm{mL})$ \\
\hline 0 & 0 & 1 & \multirow{11}{*}{$\begin{array}{l}1 \mathrm{~mL} \text { of extract }+1 \mathrm{~mL} \text { of } C \text {. } \\
\text { albicans suspension in SDB }\end{array}$} & 0 \\
\hline 4 & 0.1 & 0.9 & & 2 \\
\hline 8 & 0.2 & 0.8 & & 4 \\
\hline 12 & 0.3 & 0.7 & & 6 \\
\hline 16 & 0.4 & 0.6 & & 8 \\
\hline 20 & 0.5 & 0.5 & & 10 \\
\hline 24 & 0.6 & 0.4 & & 12 \\
\hline 28 & 0.7 & 0.3 & & 14 \\
\hline 32 & 0.8 & 0.2 & & 16 \\
\hline 36 & 0.9 & 0.1 & & 18 \\
\hline 40 & 1 & 0 & & 20 \\
\hline
\end{tabular}


added to each well to release the bounded CV. Then, the plate was read by using microtitre reader (BioTek, USA) at the wavelength of $590 \mathrm{~nm}$.

\section{Biofilm formation in 6-well microtitre plates}

The suspension of $C$. albicans cell in RPMI1640 medium was prepared as described above. A volume of $2.5 \mathrm{~mL}$ of cell suspension was pipetted onto 6-well microtitre plates. Next, $2.5 \mathrm{~mL}$ of A. ascalonicum extract with 4 different final concentrations (0 MIC, 0.25 MIC, 0.5 MIC and 1 MIC) were added into the cell suspension. The 6-well microtitre plate was covered with lid and incubated for 24 hours at $35^{\circ} \mathrm{C}$.

\section{Microscopic observation of biofilm formation}

After 24 hours, 6-well microtitre plate was viewed and examined under inverted light microscope. Photographs were taken for each concentration of $A$. ascalonicum extract.

\section{Statistical analysis}

Data analyses were performed using IBM SPSS Statistics (Version 23.0). The normality of the data was accessed using Shapiro-Wilk normality test. Results were analyzed using Kruskal-Wallis and Bonferroni correction test to determine the differences between treated and untreated groups and $P$ values $<0.05$ were considered as statistically significant.

\section{Results}

Disc diffusion assay and broth macrodilution assay

In this study, the anti-C. albicans effect of A. ascalonicum aqueous extract was screened by using disc diffusion assay. A clear zones of inhibition, $1.2 \mathrm{~cm}$ and 1.5 $\mathrm{cm}$ were observed at the $10 \mathrm{~g} / \mathrm{mL}$ and $20 \mathrm{~g} / \mathrm{mL}$ of $A$. ascalonicum aqueous extract, respectively (Figure 1). Broth macrodilution found that the minimum inhibitory concentration (MIC), the lowest concentration of $A$. ascalonicum aqueous extract that inhibited the growth of

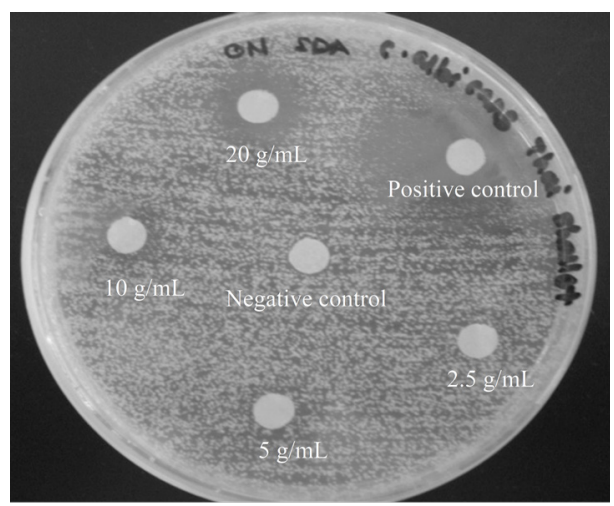

Figure 1. The disc diffusion assay showed $10 \mathrm{~g} / \mathrm{mL}$ and $20 \mathrm{~g} / \mathrm{mL}$ of Allium ascalonicum aqueous extracts inhibited the growth of Candida albicans.

\section{C. albicans was $10 \mathrm{~g} / \mathrm{mL}$ (Table 2).}

Biofilm formation assay

The Shapiro-Wilk test has indicated that the data generated for both XTT and CV assays were not normally distributed $(P<0.05)$. Therefore, the non-parametric statistical tests, Kruskal-Wallis and Bonferroni correction tests were applied in this study. Through the XTT reduction assay, significant reduction in biofilm forming activity was observed when biofilm formation of C. albicans was challenged with $A$. ascalonicum extract at $1 \mathrm{MIC}$ and $2 \mathrm{MIC}$, in comparison to untreated biofilm (Figure 2). Besides, CV assay found that the amount of biofilm formed by $C$. albicans was observed to be reduced significantly with the treatment of $A$. ascalonicum extract at 1 MIC and 2 MIC (Figure 3). The microscopic examination of C. albicans biofilm treated with $A$. ascalonicum extract was carried out by using inverted light microscope at 40X magnification to examine the anti-biofilm effect of A. ascalonicum extract, qualitatively. The results showed

Table 2. Summary of the Minimum Inhibitory Concentration (MIC) of Allium ascalonicum aqueous extracts against Candida albicans

\begin{tabular}{lc}
\hline Plant Extracts Concentration, $\mathbf{g} / \mathbf{m L}$ & Candida albicans growth \\
\hline Negative Control & Resistant \\
2 & Resistant \\
4 & Resistant \\
6 & Resistant \\
8 & Resistant \\
10 & Susceptible \\
12 & Susceptible \\
14 & Susceptible \\
16 & Susceptible \\
18 & Susceptible \\
20 & Susceptible \\
Positive Control (Clotrimazole) & Susceptible \\
\hline
\end{tabular}

The growth of $C$. albicans was inhibited by $10 \mathrm{~g} / \mathrm{mL}$ of $A$. ascalonicum.

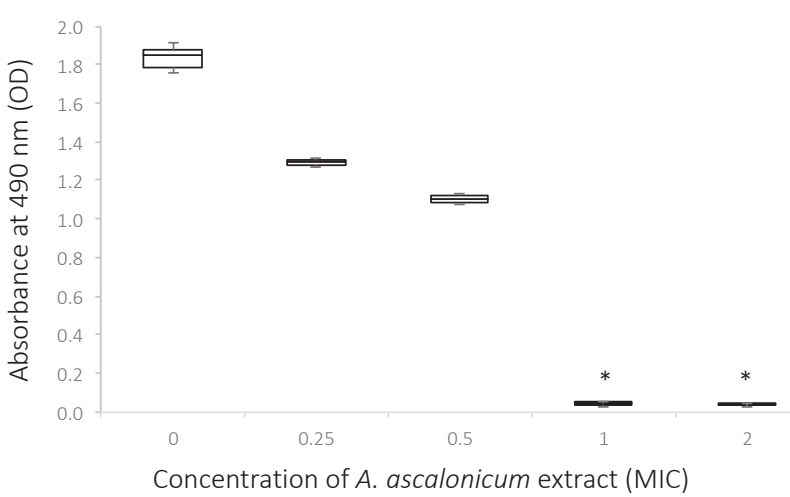

Figure 2. Determination of the effect of Allium ascalonicum aqueous extract on Candida albicans biofilm formation activity using XTT Assay. Box-plot shows the biofilm formation activity under different concentration of treatment after incubation for 24 hours, at $490 \mathrm{~nm}$ by using XTT reduction assay. A significant reduction $\left({ }^{*}\right)$ of biofilm formation activity was observed at $1 \mathrm{MIC}$ and $2 \mathrm{MIC}(P$ value $<0.05)$. 
that the biofilm density of $C$. albicans was reduced with the increasing concentration of $A$. ascalonicum extract, compared to biofilm formation without any treatment (Figure 4).

\section{Discussion}

Candidiasis is a type of opportunistic infection in human caused by Candida species. C. albicans is the major etiological agent which constitutes 44.2\%, among 1114 clinical isolations in Malaysia (27). In past 2 decades, the prevalence of candidiasis has risen and this led to the increase in the usage of antifungal therapies such as azole drug. With the extensive usage of azole drug, the problem with the development of resistance toward azoles by Candida species has also risen with both primary and secondary resistance (28). Furthermore, the persistence of Candida species biofilm on medical devices surfaces such as indwelling catheter has also contributed to the rising number of invasive candidiasis cases (12). The formation of biofilm is also linked to the enhanced capability of Candida to resist antifungal (29), which leads to the challenge in the treatment of candidiasis. Thus, the purpose of this study was to evaluate antifungal and anti-biofilm properties of the aqueous extract from A. ascalonicum against the predominance Candida species, Candida albicans which can be applied as an economic surface disinfectant or novel antifungal compound. The disc diffusion assay suggested that the effective concentration of $A$. ascolonicum aqueous extract to inhibit the growth of C. albicans was at $10 \mathrm{~g} / \mathrm{mL}$ (Figure 1) and broth microdilution assay was determined the MIC of A. ascalonicum aqueous extract to be $10 \mathrm{~g} / \mathrm{mL}$ (Table 2), where the growth of C. albicans was completely stunted. This is in line with the previous study conducted by Mahmoudabadi and Nasery (30) where fresh crude shallot juice (A. ascalonicum Linn. (Liliaceae)) presented with antifungal activity against $C$. albicans, as well as saprophytic fungi and dermatophytes. However, the

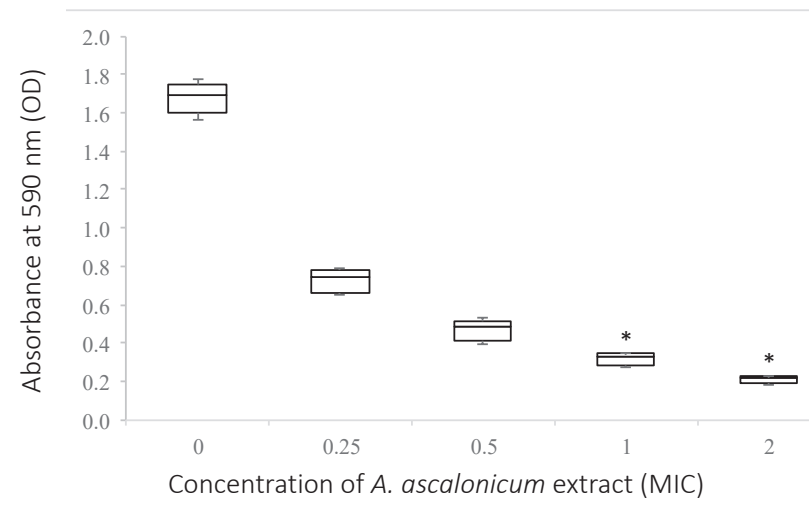

Figure 3. Determination of the effect of Allium ascalonicum aqueous extract on Candida albicans biofilm formation using CV assay. Boxplot shows the amount of biofilm formed under different concentration of treatment after incubation for 24 hours, at $590 \mathrm{~nm}$ by using CV assay. A significant reduction (*) of biofilm formed was observed at 1 $\mathrm{MIC}$ and 2 MIC $(P$ value $<0.05)$.

MIC was not comparable as the authors designated the concentration of $A$. ascalonicum aqueous extract in the form of percentage, rather than in weight per volume. Besides, several studies have also highlighted the potential antifungal effect of A. ascalonicum in combating C. albicans $(31,32)$, at $\mathrm{mg} / \mathrm{mL}$ level. Notably, the extraction methods in both studies were different from this study, where $A$. ascalonicum has undergone complex and time-consuming extraction procedure while current study applied the direct yet simple $(<1$-hour procedure) aqueous method to extract the antifungal compound from A. ascalonicum. Followed by the susceptibility test, the potential of $A$. ascalonicum extract to combat the biofilm of C. albicans was evaluated through both XTT assay and CV assay. XTT is a yellow salt that is reduced by mitochondrial dehydrogenase of metabolically active yeast cell (33) and is employed in quantitating the biofilm formation activity (34) while CV assay is a basic dye which binds to negatively charged extracellular molecule in mature biofilm (35) and CV assay can be applied in measuring the amount of biofilm formed $(25,26)$. In this study, both XTT assay and $\mathrm{CV}$ assay showed that $A$. ascalonicum aqueous extract exhibited an inhibitory effect on biofilm formation of C. albicans (Figures 3 and 4). Moreover, the increased in the concentration of $A$. ascalonicum extract has resulted in a greater reduction of biofilm formation activity and biofilm density (Figures 2 and 3). These observations were further verified with the microscopic examination

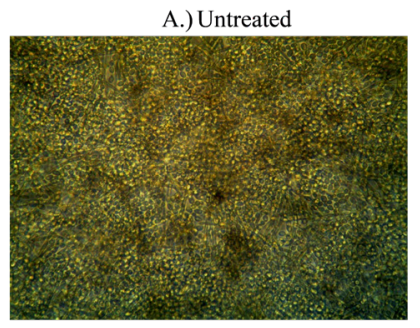

B.) $0.25 \mathrm{MIC}$

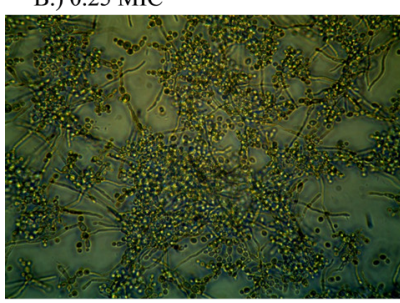

C.) 1 MIC

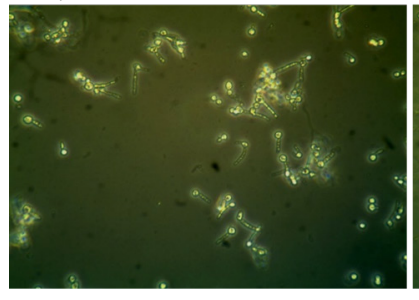

Figure 4. Biofilm formation observed after 24 hours with respective treatment applied. A.) without treatment B.) $0.25 \mathrm{MIC}$, C.) $0.5 \mathrm{MIC}$, D.) $1 \mathrm{MIC}$ and $\mathrm{E}$.) $2 \mathrm{MIC}$ at $40 \mathrm{X}$ magnification. A reduction of activity was observed with increasing concentration of treatment. 
as biofilm density decreased with the treatment of $A$. ascalonicum extract (Figure 4).

\section{Conclusion}

In short, through a simple and cost-effective aqueous extraction method, this study revealed the potential of A. ascalonicum to inhibit the growth of C. albicans at the concentration of $10 \mathrm{~g} / \mathrm{mL}$ as well as to inhibit the biofilm formation activity of $C$. albicans. The results from this study are beneficial for the development of economicallysound surface disinfectant which could be useful in managing the Candida biofilm contamination.

\section{Acknowledgments}

This paper was derived partly from B.Sc theses of Tzu Shan Ng and Ban Shui Ong. The authors are in debt for the financial support provided by the Department of Biomedical Sciences, Faculty of Medicine and Health Sciences, Universiti Putra Malaysia.

\section{Authors' contributions}

TSN and BSO performed the experiment. TSN and LJL wrote the manuscript. TSN, BSO and PPC designed and conceptualized the experiment designed. All read and confirmed final version of the manuscript for publication.

\section{Conflict of interests}

The authors declared no competing interests.

\section{Ethical considerations}

Ethical issues (including plagiarism, misconduct, data fabrication, falsification, double publication or submission redundancy) have been completely observed by the authors.

\section{Funding/Support}

Final year student project allocation, Department of Biomedical Sciences, Faculty of Medicine and Health Sciences, Universiti Putra Malaysia.

\section{References}

1. Bongomin F, Gago S, Oladele RO, Denning DW. Global and multi-national prevalence of fungal diseases-estimate precision. J Fungi (Basel). 2017;3(4). doi: 10.3390/ jof3040057.

2. Ng TS, Mohd Desa MN, Sandai D, Chong PP, Than LT. Phylogenetic and transcripts profiling of glucose sensing related genes in Candida glabrata. Jundishapur J Microbiol. 2015;8(11):e25177. doi: 10.5812/jjm.25177.

3. Hawksworth DL. Hawksworth DL. The magnitude of fungal diversity: the 1.5 million species estimate revisited. Mycol Res. 2001;105(12):1422-32. doi: 10.1017/ S0953756201004725.

4. Cauchie M, Desmet S, Lagrou K. Candida and its dual lifestyle as a commensal and a pathogen. Res Microbiol. 2017;168(9-10):802-10. doi: 10.1016/j.resmic.2017.02.005.

5. Whiteway M, Nantel A. Genomic Analysis of Cellular
Morphology in Candida albicans. In: Brown AJP, ed. Fungal Genomics. Berlin: Springer; 2006:147-59.

6. Ng TS, Desa MNM, Sandai D, Chong PP, Than LTL. Growth, biofilm formation, antifungal susceptibility and oxidative stress resistance of Candida glabrata are affected by different glucose concentrations. Infect Genet Evol. 2016;40:331-8. doi: 10.1016/j.meegid.2015.09.004.

7. Silva S, Negri M, Henriques M, Oliveira R, Williams DW, Azeredo J. Adherence and biofilm formation of nonCandida albicans Candida species. Trends Microbiol. 2011;19(5):241-7. doi: 10.1016/j.tim.2011.02.003.

8. Fidel PL Jr, Vazquez JA, Sobel JD. Candida glabrata: review of epidemiology, pathogenesis, and clinical disease with comparison to C. albicans. Clin Microbiol Rev. 1999;12(1):80-96.

9. Ng KP, Kuan CS, Kaur H, Na SL, Atiya N, Velayuthan RD. Candida species epidemiology 2000-2013: a laboratorybased report. Trop Med Int Health. 2015;20(11):1447-53. doi: $10.1111 /$ tmi.12577.

10. Diekema D, Arbefeville S, Boyken L, Kroeger J, Pfaller M. The changing epidemiology of healthcare-associated candidemia over three decades. Diagn Microbiol Infect Dis. 2012;73(1):45-8. doi: 10.1016/j.diagmicrobio.2012.02.001.

11. Bouza E, Guinea J, Guembe M. The role of antifungals against Candida biofilm in catheter-related candidemia. Antibiotics (Basel). 2014;4(1):1-17. doi: 10.3390/ antibiotics4010001.

12. Kojic EM, Darouiche RO. Candida infections of medical devices. Clin Microbiol Rev. 2004;17(2):255-67.

13. Ramage G, Saville SP, Thomas DP, Lopez-Ribot JL. Candida biofilms: an update. Eukaryot Cell. 2005;4(4):633-8. doi: 10.1128/ec.4.4.633-638.2005.

14. Crump JA, Collignon PJ. Intravascular catheter-associated infections. Eur J Clin Microbiol Infect Dis. 2000;19(1):1-8. doi: 10.1007/s100960050001.

15. Douglas LJ. Candida biofilms and their role in infection. Trends Microbiol. 2003;11(1):30-6.

16. Lamfon H, Porter SR, McCullough M, Pratten J. Susceptibility of Candida albicans biofilms grown in a constant depth film fermentor to chlorhexidine, fluconazole and miconazole: a longitudinal study. J Antimicrob Chemother. 2004;53(2):383-5. doi: 10.1093/jac/dkh071.

17. Nikawa $H$, Nishimura $H$, Hamada $T$, Makihira $S$, Samaranayake LP. Relationship between thigmotropism and Candida biofilm formation in vitro. Mycopathologia. 1998;144(3):125-9.

18. Perfect JR. "Is there an emerging need for new antifungals?". Expert Opin Emerg Drugs. 2016;21(2):129-31. doi: $10.1517 / 14728214.2016 .1155554$.

19. Fattorusso E, Iorizzi M, Lanzotti V, Taglialatela-Scafati O. Chemical composition of shallot (Allium ascalonicum Hort.). J Agric Food Chem. 2002;50(20):5686-90.

20. Leelarungrayub N, Rattanapanone V, Chanarat N, Gebicki JM. Quantitative evaluation of the antioxidant properties of garlic and shallot preparations. Nutrition. 2006;22(3):26674. doi: 10.1016/j.nut.2005.05.010.

21. Adeleye IA, Onubogu CC, Ayolabi CI, Isawumi AO, Nshiogu ME. Screening of crude extracts of twelve medicinal plants and "wonder-cure" concoction used in Nigeria unorthodox medicine for activity against Mycobacterium 
tuberculosis isolated from tuberculosis patients sputum. Afr J Biotechnol. 2008;7(18):3182-7.

22. Wang HX, Ng TB. Ascalin, a new anti-fungal peptide with human immunodeficiency virus type 1 reverse transcriptase-inhibiting activity from shallot bulbs. Peptides. 2002;23(6):1025-9.

23. Fujita SI, Senda Y, Nakaguchi S, Hashimoto T. Multiplex PCR using internal transcribed spacer 1 and 2 regions for rapid detection and identification of yeast strains. J Clin Microbiol. 2001;39(10):3617-22. doi: 10.1128/ jcm.39.10.3617-3622.2001.

24. Silva Mdo R, Costa MR, Miranda AT, Fernandes Ode F, Costa CR, Paula CR. Evaluation of Etest and macrodilution broth method for antifungal susceptibility testing of Candida sp strains isolated from oral cavities of AIDS patients. Rev Inst Med Trop Sao Paulo. 2002;44(3):121-5.

25. Pierce CG, Uppuluri P, Tristan AR, Wormley FL Jr, Mowat E, Ramage G, et al. A simple and reproducible 96-well platebased method for the formation of fungal biofilms and its application to antifungal susceptibility testing. Nat Protoc. 2008;3(9):1494-500. doi: 10.1038/nport.2008.141.

26. Pitts B, Hamilton MA, Zelver N, Stewart PS. A microtiterplate screening method for biofilm disinfection and removal. J Microbiol Methods. 2003;54(2):269-76.

27. Ng KP, Madasamy M, Saw TL, Baki A, He J, Soo-Hoo TS. Candida biotypes isolated from clinical specimens in Malaysia. Mycopathologia. 1998;144(3):135-40.

28. Perlin DS. Antifungal drug resistance: do molecular methods provide a way forward? Curr Opin Infect Dis. 2009;22(6):568-73. doi: 10.1097/QCO.0b013e3283321ce5.

29. Chandra J, Kuhn DM, Mukherjee PK, Hoyer LL, McCormick
T, Ghannoum MA. Biofilm formation by the fungal pathogen Candida albicans: development, architecture, and drug resistance. J Bacteriol. 2001;183(18):5385-94.

30. Zarei Mahmoudabadi A, Gharib Nasery MK. Anti fungal activity of shallot, Allium ascalonicum Linn. (Liliaceae), in vitro. J Med Plant Res. 2009;3(5):450-3.

31. Moghim H, Taghipoor S, Shahinfard N, Kheiri S, Heydari Z, Rafieian S. Antifungal effects of Allium ascalonicum, Marticaria chamomilla and Stachys lavandulifolia extracts on Candida albicans. J HerbMed Pharmacol. 2014;3(1):914.

32. Khodavandi A, Alizadeh F, Namvar F, Mohamad R, Chong PP. Anti-Candida potential of Allium ascalonicum Linn: antibiofilm activity and biomolecular mechanism of action. J Pure Appl Microbiol. 2014;8:349-56.

33. Hawser SP, Norris H, Jessup CJ, Ghannoum MA.Comparison of a 2,3-bis(2-methoxy-4-nitro-5-sulfophenyl)-5[(phenylamino)carbonyl]-2H-t etrazolium hydroxide (XTT) colorimetric method with the standardized National Committee for Clinical Laboratory Standards method of testing clinical yeast isolates for susceptibility to antifungal agents. J Clin Microbiol. 1998;36(5):1450-2.

34. Henriques M, Azeredo J, Oliveira R. Candida albicans and Candida dubliniensis: comparison of biofilm formation in terms of biomass and activity. Br J Biomed Sci. 2006;63(1):511.

35. Li X, Yan Z, Xu J. Quantitative variation of biofilms among strains in natural populations of Candida albicans. Microbiology. 2003;149(Pt 2):353-62. doi: 10.1099/ mic.0.25932-0. 